\title{
Viewpoint
}

\section{Seasonal variations in Nigeria: understanding COVID-19 transmission dynamics and immune responses}

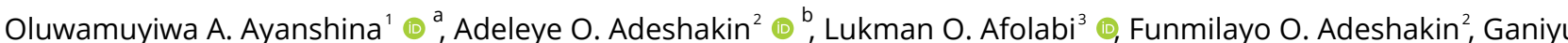
O. Alli-Balogun ${ }^{4}$, Dehong Yan ${ }^{5}$, Samuel Essien-Baidoo ${ }^{6}$, Xiaochun Wan $^{7}$ (1)

\begin{abstract}
1 Department of Biochemistry, Faculty of Basic Medical Sciences, College of Medicine, University of Lagos, Idi-araba, Lagos, Nigeria; Department of Chemical Sciences, College of Natural and Applied Sciences, Crescent University Abeokuta, Abeokuta, Ogun State, Nigeria, ${ }^{2}$ Centre for Protein and Cell-based Drugs, Institute of Biomedicine and Biotechnology, Shenzhen Institutes of Advanced Technology, Chinese Academy of Sciences, Shenzhen, PR China; University of Chinese Academy of Sciences, Beijing, PR China, ${ }^{3}$ Centre for Protein and Cell-based Drugs, Institute of Biomedicine and Biotechnology, Shenzhen Institutes of Advanced Technology, Chinese Academy of Sciences, Shenzhen, PR China; University of Chinese Academy of Sciences, Beijing, PR China; Department of Biochemistry, Faculty of Science, Federal University Dutse, Jigawa State, Nigeria, ${ }^{4}$ University College London (UCL) Institute of Ophthalmology, London, United Kingdom, ${ }^{5}$ Centre for Protein and Cell-based Drugs, Institute of Biomedicine and Biotechnology, Shenzhen Institutes of Advanced Technology, Chinese Academy of Sciences, Shenzhen, PR China, ${ }^{6}$ Department of Medical Laboratory Science, School of Allied Health Sciences, University of Cape Coast, Ghana, ${ }^{7}$ Centre for Protein and Cell-based Drugs, Institute of Biomedicine and Biotechnology, Shenzhen Institutes of Advanced Technology, Chinese Academy of Sciences, Shenzhen, PR China; University of Chinese Academy of Sciences, Beijing, PR China; Shenzhen BinDeBioTech Co., Ltd, Shenzhen, PR China

Keywords: nigeria, immune responses, seasonal variations, covid-19

https://doi.org/10.29392/001c.14600
\end{abstract}

\section{Journal of Global Health Reports}

Vol. 4, 2020

\begin{abstract}
There is a global rise in the emergence of infectious diseases and the enigmatic coronavirus disease 2019 (COVID-19) being the most recent one. It is ravaging the world with little understanding of its etiology and factors affecting its transmission dynamics. Meanwhile, seasonal variations in weather are major factors impacting infectious disease transmission patterns. Developing countries are likely to be most affected by weather changes that could impact on the spread and control of infectious diseases. In Nigeria, weather conditions alternate between rainy and dry seasons. Conditions such as rainfall, humidity and sunlight had been reported to influence host susceptibility to infectious diseases. On the other hand, these weather elements have a direct or indirect impact on the level of vitamin D availability. More so, vitamin C and D supplementation were highlighted to enhance immunity in COVID-19 patients. Thus, understanding the impact of weather changes in transmission dynamics and boosting immune response to COVID-19 through vitamin supplementation in infected patients may be crucial as the rainy season fully sets in.
\end{abstract}

Change in weather is one of the factors predisposing the spread of infectious diseases. ${ }^{1,2}$ Since the outbreak of the coronavirus disease 2019 (COVID-19) in Wuhan, Hubei Province of China, almost all regions of the world are battling with the scourge; and its transmission is yet to diminish. Although research into weather pattern and COVID-19 transmission dynamics relationship is still rudimentary, the world has been experiencing this viral spread over the past eight months (December 2019 - August 2020); and, given this timeline, most countries are now having COVID-19 incidence across seasonal periods which are characterized by gradually changing weather conditions. Initially, the outbreak began in winter across several continents including Asia, Europe, America, and a few countries in Africa. With time, spring set in, and gradually summer is approaching, yet a good number of COVID-19 cases have been reported and still rising. In terms of experiencing COVID-19 cases across seasons, Nigeria is no exception to this as the infection is gradually cutting across her two major seasons known as dry (harmattan) and wet (rainy) seasons. The wet season spans April to October while dry season ranges from November to March. ${ }^{3}$ Nigeria's COVID-19 index case was reported on February 27, 2020, during the dry season. Meanwhile, as of August 3, 2020, a total number of 44,129 COVID-19 cases have been reported.

Several studies revealed that certain viruses causing respiratory infections such as coronaviruses or rhinovirus (RV) do so in the seasons in which they are most active especially in the spring and autumn. ${ }^{4}$ Rory et al. recently reported the seasonality of viral activities by varying meteorological factors (temperature, dew point, relative humidity, and humidity range). ${ }^{5}$ Dowell also reported the course of infectious diseases may be dependent on weather/climate patterns, pathogen prevalence/virulence, or host behavioral pat- 
terns. ${ }^{6}$ It is noteworthy that a study conducted in Europe from 1950-2010 also reported varying infectious diseases outbreaks as weather transcends from summer to winter and vice versa. ${ }^{7}$ In the temperate regions, influenza reportedly displays seasonality in transmission due to winter. ${ }^{8}$ In the tropics, particularly Nigeria, the seasonality of influenza outbreaks occurs mostly during the wet season, but cases of influenza have also been documented during dry seasons. ${ }^{3,9}$ Due to the semblance of certain flu-like symptomatic features that COVID-19 shares with influenza, there might be reasons to think weather changes might lead to upsurge of COVID-19 transmission. Herein, the question remains if there be any link between changing weather on immune response and transmission of COVID-19 in Nigeria?

\section{UPDATE ON THE INCIDENCE OF COVID-19 CASES AND WEATHER REPORT IN NIGERIA}

Exactly 159 days, between late February and early August, since the index case of COVID-19 in Nigeria, several cases have been reported in almost all states of the federation, including the federal capital territory (FCT). According to Nigeria Center for Disease Control (NCDC), the country as at August 3, 2020 has a record of 44,129 total number of confirmed cases, 22,570 total number of active cases, 896 total number of deaths, and 20,663 total number of recovered cases. Based on the timeline of NCDC epidemiological reports, we can deduce that COVID-19 incidence in Nigeria might be sustained across the dry and wet season. This informed our quest to explore the possible link between transmission dynamics of COVID-19, seasonal changes in Nigeria, and immune response preparedness.

We embarked on a 13-week survey between February 29 and June 1, 2020, culling Nigeria weather forecast data from the World Weather Information Service of the World Meteorological Organization in collaboration with Nigerian Meteorological Agency (NIMET) as well as COVID-19 case report from NCDC COVID-19 situation reports. ${ }^{10,11}$ Fluctuations in average weather temperatures were markedly experienced across the period of the survey with the gradual plunging of the temperature mostly experienced around April and May (Figure 1). However, this was met with a hyperbolic rise in the number of total COVID-19 confirmed cases and recovery reported within the period (Figure 1). Within the reported period, average temperatures gradually plummeted and this was accompanied by an upsurge in the rate of new infections, a modest rise in recovery rates, while death rates remain low (Figure 2).

\section{VITAMIN D DEFICIENCY AND RISK OF COVID-19 INFECTION}

Vitamin D is a steroid hormone that regulates innate and adaptive immune responses. ${ }^{12}$ It acts as an immunomodulatory, anti-inflammatory, antimicrobial and antioxidant agent that suppresses immune-mediated disease progression. ${ }^{13}$ Vitamin D receptors are well expressed by host respiratory epithelial tissue and immune cells such as macrophages, monocytes, $\mathrm{T}$, and $\mathrm{B}$ cells. ${ }^{14,15}$ Optimal serum vitamin D mediates immune response to viral respiratory infections. ${ }^{15}$ In COVID- 19 patients, SAR-CoV-2 binds angiotensin-converting enzyme 2 (ACE2), a receptor in the respiratory tract that induces the expression of surfactant associated protein B. ${ }^{16}$ Previous knowledge revealed type II pneumocytes as the primary targets of coronaviruses with high expression of ACE2 receptors. ${ }^{17}$ In COVID-19 patients, impairment of pneumocytes reduced surfactant level with concomitantly increased surface tension in infected people. ${ }^{18}$

Ironically, an element of weather - sunlight is the main source of vitamin $\mathrm{D},{ }^{19}$ which is inevitably deficient in over $50 \%$ population worldwide. ${ }^{20}$ Weather variations due to seasonality have been attributed to micronutrient deficiency in human, which has debilitating effect on immune system. ${ }^{21}$ This micronutrient deficiency may favor the progression of COVID-19 reported to thrive better in the underage, elderly and those with underlying diseases, who are apparently immunocompromised. Likewise, inadequate exposure to sunlight has been linked to decrease in skin 7-dehydrocholesterol which is the main precursor for vitamin D synthesis. ${ }^{22}$ Vitamin D deficiency is documented in various Nigerian populations and such populations, especially the elderly and immunocompromised patients, are highly susceptible to COVID-19 infection. ${ }^{23,24}$ Vitamin D deficient population such as the elderly ${ }^{25}$ and patients suffering from bronchiectasis or immunodeficiency disorders ${ }^{12}$ are at high risk of contracting COVID-19. In Chicago, data revealed over 50\% of COVID-19 cases and approximately $70 \%$ of COVID-19 death were reported in African-Americans $^{26}$ who are at higher risk for vitamin D deficiency. ${ }^{27}$

Generally the public health strategies that have been employed in tackling viral outbreaks have usually been hinged on hygiene standards (non-pharmacological intervention (NPI)) and pharmacological use of vaccines or drugs alike. ${ }^{28}$ At present, NPI is under use in this current pandemic while research into pharmacological intervention are yet underway. Nonetheless, given the role some nutritional components play in mediating or boosting immune response, studies have recommended inclusion of nutritional intervention among the public health strategies to fight COVID-19.28,29 Vitamin D is suggested as a micronutrient that has the potential to abate the risk of viral infection including Dengue virus, rotavirus and COVID-19.22,28

Literature is yet to document any clinical trial outcome confirming the relationship between vitamin supplementation and immune response among individuals infected with COVID-19. ${ }^{30}$ Presently, evidences available are based of meta-analyses of previous data in correlation with current COVID-19 cases reported across different regions of the world. Recently, a meta-analyses performed with the aim of extrapolating findings from a pool of previous studies to advise management of COVID-19 patient, reported the immunomodulatory enhancement of vitamin $\mathrm{D}$ and some micronutrients against viral infections. ${ }^{31}$ Arboleda et al., used an in vitro Dengue virus model to explore the role of vitamin D against viral infection, and found that doses as high as 4000 IU of vitamin D over a 10-day period can adequately decrease cytokine storm that characterizes viral infection ${ }^{32}$; hence extrapolating similar outcome for COVID-19. ${ }^{33}$ On the basis of age-adjusted COVID-19 case 


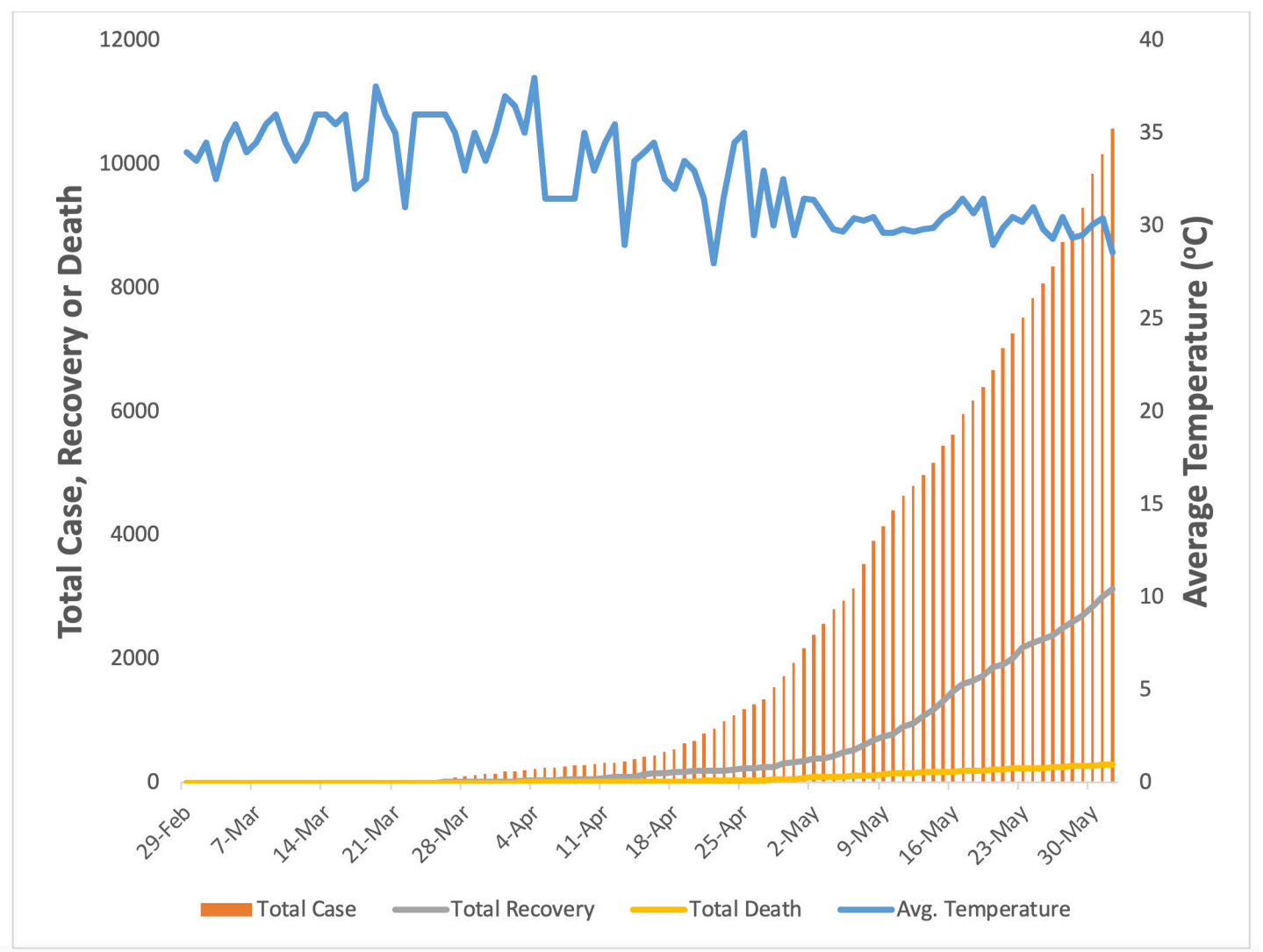

Figure 1. Total distribution of COVID-19 pandemic and average weather temperature in Nigeria between February 29 and June 1, 2020.

fatality ratio (CFR) of different countries as well as status of vitamin $\mathrm{D}$ in the countries as given by previous studies, Daneshkhah et al., inferred that COVID-19 CFR is higher in countries with average lower levels of vitamin $\mathrm{D}$; therefore suggesting vitamin D can elicit suppression of cytokine storm that characterizes fatal cases of COVID-19. ${ }^{34}$

Vitamin D as an adjunct medication was highlighted recently as a promising therapeutic approach to modulate body immune responses in fighting COVID-19 infection. ${ }^{35}$ Moreover, it has been reported that vitamin D supplementation resulted in elevated serum levels of vitamin D among elderly and those who had lower levels of vitamin D due to increased time spent indoors. ${ }^{36}$ Interestingly, COVID-19 lockdown or onset of winter are scenarios highlighted for insufficient sunlight. With the onset of rainy season in Nigeria, sunlight source of vitamin D might be reduced and coupled with partial lockdown in various parts of the country reducing citizen's contact to this element. As such, there is a need to boost vitamin $\mathrm{D}$ levels in our population thus enhancing immunity of the populace against possible upsurge in COVID-19 as well as other regular rainy season respiratory-tract infections.

\section{POTENTIAL BENEFITS OF VITAMIN C AS AN IMMUNE BOOSTER FOR COVID-19 INFECTION}

Vitamin C (ascorbic acid or ascorbate) is a water-soluble vi- tamin that mediates essential biological processes. It possesses antioxidant, anti-inflammatory, anti-microbial, antiviral and immunostimulatory properties. Notably, it plays a key role in enhancing body's immune function to resist or overcome infection and even aids cancer therapy. $37-39$ Studies have reported the role of vitamin $\mathrm{C}$ in promoting the development, maturation of $\mathrm{NK}$ and $\mathrm{T}$ cells critical for immune responses against viral attack. ${ }^{40}$ During infection, there is an enhanced turnover of vitamin $\mathrm{C}$ leading to its depletion in the infected person and increased requirement for vitamin $\mathrm{C}$ depending on the severity of infection. ${ }^{41}$ In severe conditions, there is need for intravenous (IV) administration of vitamin $\mathrm{C}$ in gram doses to achieve sufficient amount in host necessary to compensate for its lost. ${ }^{42}$ The question remains if high doses of vitamin $\mathrm{C}$ can prevent or augment treatment for COVID-19 in Nigeria?

Generally, vitamin $\mathrm{C}$ as an antioxidant agent inhibits reactive oxygen species production and cytokine storm - a hallmark of acute respiratory disease syndrome (ARDS) thus protecting cells and tissues from oxidative stress and dysfunction. In a study involving 29 patients with COVID-19 in Huangzhou, China, 93\% (27) of the patients expressed increased high sensitive C-reactive protein - a marker of oxidative stress and inflammation in blood. ${ }^{43} \mathrm{An}$ other study in China reported that high doses (10-20g per day) IV vitamin $C$ for 8-10h was successful in the treatment of 50 moderate to severe COVID-19 patients. ${ }^{44}$ Vitamin C reduced patient's dependency on ventilators and all pa- 


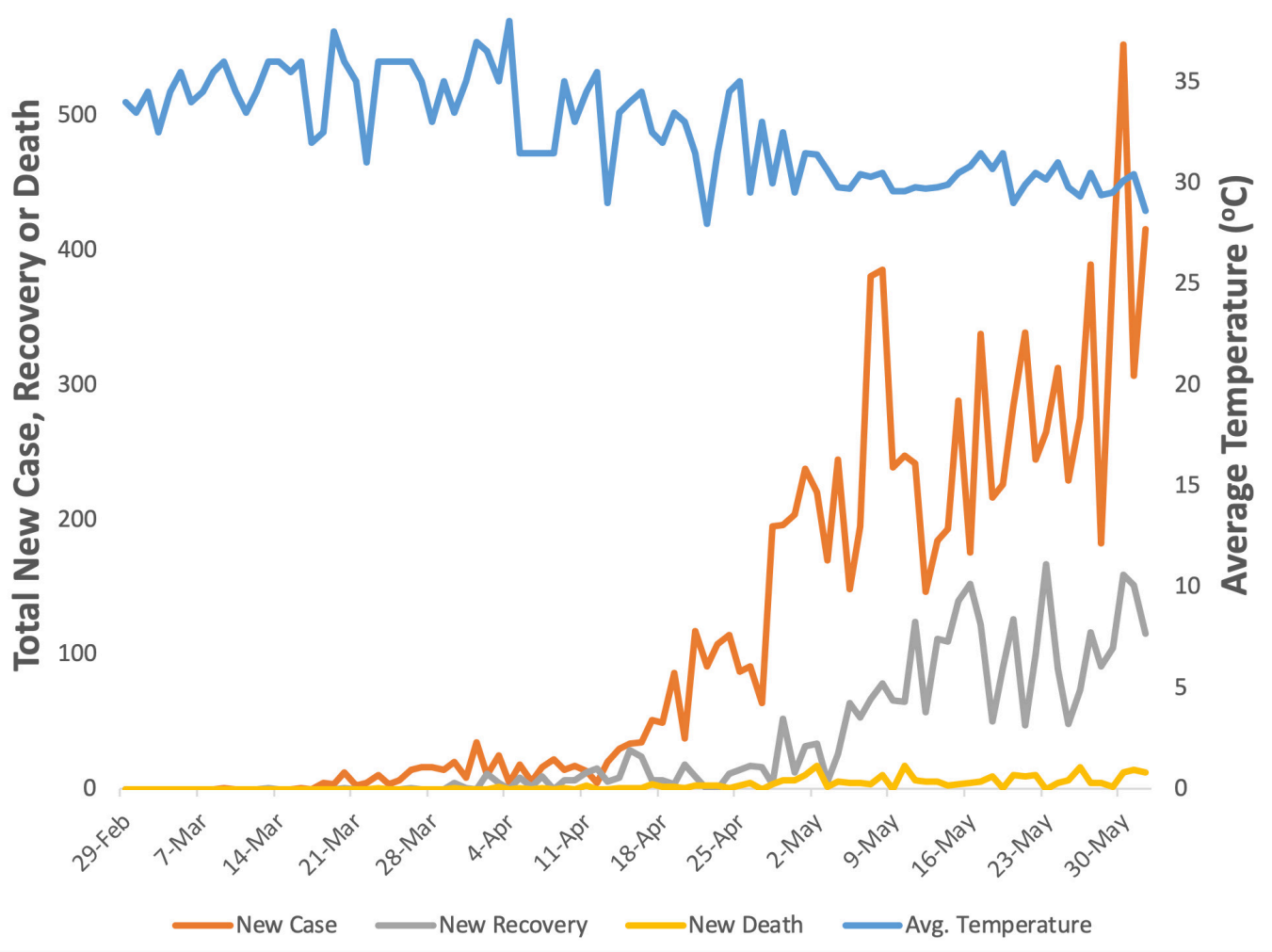

Figure 2: Daily distribution of COVID-19 pandemic and average weather temperature in Nigeria between February 29 and June 1, 2020.

tients were eventually cured and discharged. It is important to state that high-dose vitamin $\mathrm{C}$ has been clinically administered for several decades and recently a team of $\mathrm{NIH}$ researchers documented that $1.5 \mathrm{~g} / \mathrm{kg}$ body weight is safe and without any obvious toxicological effects. ${ }^{45}$ In terms of immune system boost, Mebaksh et al., reported that intravenous administration of high dose vitamin $\mathrm{C}$ can lead to the suppression of immune cells hyperactivity due to COVID-19 triggered pneumonia symptom that causes injury to the lungs in severe COVID-19 patients. ${ }^{46}$

An ongoing phase 2 clinical trial to investigate the effect of vitamin C infusion on COVID-19 patients in Wuhan, China 2020 was registered on clincialtrials.gov (Identifier: NCT04264533). In this study, 140 infected patients would be treated with placebo control or IV vitamin $C$ at a dose of $12 \mathrm{~g}$ twice daily for 7 days. The investigators would assess the requirement of the treated patients for ventilation, vasopressor drugs, respiratory indexes, ICU length of stay, organ failure scores and 28-days mortality. More recently, another clinical trial to commence in June, 2020 and end by May, 2021 was registered on clincialtrials.gov (Identifier: NCT04344184). This study would involve 200 COVID-19 patients with acute lung injury in Virginia, USA to be treated with either $5 \%$ dextrose or IV vitamin C at a dose of $300 \mathrm{mg} /$ $\mathrm{kg}$ daily for 3 days. They would assess requirement for mechanical ventilation, acute-inflammation index, organ failure score and 28-days mortality. Although clinical trials on investigating the role of vitamin C in COVID-19 are very few and will not be completed soon, it will eventually provide relevant information on how vitamin $\mathrm{C}$ can reduce symptoms of future viral outbreak(s).

The most important thing here is that high dose vitamin $\mathrm{C}$ is being used as an adjuvant therapy rather than taking 500mg vitamin $C$ and expecting a cure from COVID-19 infection. Presently, we do not know if oral administration of vitamin C could prevent COVID-19, however, we advise all Nigerians especially the healthcare personnel and people with health complications - who are at greater risk of getting infected to implement daily intake of vitamin $\mathrm{C}$ as a nutritional supplement.

\section{HOW CHANGES IN WEATHER WILL AFFECT HOST IMMUNE RESPONSE TO COVID-19 INFECTION}

Epidemiological data reveal that variations in temperature, rainfall, and humidity can have profound impact on the transmission of infectious disease. ${ }^{47}$ Meanwhile, accurate prediction on how climate change will affect the transmission dynamics of viral infection is challenging due to the complexity of interactions existing between nature and human activities. More so, there are diverging opinions on how weather changes could affect the spread and management of COVID 19 to date. Nonetheless, yearly fluctuations in viral infection patterns observed in seasonal flu and pre- 
vious epidemics such as yellow fever provide some clue on the immune system's ability to fight respiratory infection. It is important to note that a host's physiologic response towards any pathogen is stimulated by a cascade of immune reactions that are dependent on the integrity of the immune system.

Several scientists have proposed the relationship between cold weather and disease onset, progression, or its spreads via a negative influence on the immune system. ${ }^{48,49}$ Vitamin D deficiency due to inadequate exposure to sunlight in winter or cold weather conditions has been linked to an increased rate of viral infection from person to person. ${ }^{35}$ Similarly, animal studies showed low ambient temperature as seen in rainy weather attenuates immune responses. ${ }^{2,49,50}$ Besides the current phased ease on lockdown in Nigeria, during cold weather or rainy season, it is expected that people would spend more time indoors; and this has the potential of containing the virus spread within a confined area and ease the rigor of effective contact tracing. On the contrary, this may disproportionately or disadvantageously reduce exposure to sunlight, which may physiologically affect Vitamin D balance.

Studies reported that antiviral defense responses of mouse and primary human airway epithelial cells infected with RV, the common cold virus, are temperature-dependent. ${ }^{49,51,52}$ It was observed that the induction of ribonuclease L (RNase L) and interferon (IFN) stimulated genes in the epithelial airways suppressed viral replication at a warm temperature. Temperature-dependent IFN release in response to RV was mediated by mitochondrial antiviralsignaling proteins (MAVs), an essential protein for antiviral innate immunity. ${ }^{52}$ Importantly, it was observed that blockade of MAVs or IFN receptors in the infected airway cells led to an increased rate of viral replication. ${ }^{51,52}$ Thus, these studies highlight the crucial role played by host immune response in determining the replication, survival, or possible transmission of respiratory tract related viral infection such as COVID-19; and how temperature modulates this crucial role.

Lavoy et al., reported the immunological changes that occur due to exercising in warm (hot) or cold environments. ${ }^{53}$ They expressed reductions in natural killer (NK) cell population and a concomitant decrease in Type 1 (Th1) and Type 2 (Th2) cytokines that are responsible for combating pathogens intracellularly and extracellularly in hot temperatures. Furthermore, cold temperatures bring about increased mucus viscosity, ciliary activity reduction in the upper respiratory system, high levels of corticosteroids and catecholamines stimulation of immune responses such as leukocytosis, inflammatory mediators' reduction and inflammatory cells adhesion molecules expression decrease. ${ }^{53}$ Recent studies have reported decreased population and impaired activity of lymphocytes, mainly NK and $\mathrm{T}$ cells to correlate with disease severity in COVID-19 patients. ${ }^{54-56}$ These indicate that COVID-19 infection can interfere with antiviral immune responses. In light of this, an uninfected individual with reduced NK and T cell numbers could be susceptible to SARS-CoV-2 and its complications if infected. This may contribute to the increased human susceptibility to COVID-19 across various geographical regions.
In a related study, Jingui and colleagues reported a linear correlation between ambient temperature and number of COVID-19 cases from 122 cities in China. ${ }^{57}$ Their evidence had no support for mitigation in transmission dynamics with changes in weather conditions. It is also important to note that preventive measures to inactivate coronavirus on reusable medical devices to ensure the safety of scientists and medical personnel having direct or indirect contact with infected patients/samples suggests near boiling point temperature for the complete shutdown of SARSCoV-2 nucleic acid. ${ }^{58}$

We suggest that Nigerians should take individual measures to enhance their immune responses by implementing diets rich in vitamins or other immune boosters in curtailing the spread of the virus. It is therefore pertinent for a country like Nigeria gradually transiting into the rainy season to consider the influence these changes in weather conditions could have on the transmission of COVID-19 or host immune response to therapy of infected patients.

\section{LESSONS LEARNED FROM COVID 19 TO PREVENT FUTURE DISEASES LIKE SARS AND MERS IN NIGERIA}

Until recently, there has not been an outbreak of coronaviruses in Nigeria and the country had her share in the COVID-19 pandemic as the first country to report coronavirus case in sub-Saharan Africa. ${ }^{59}$ Relatively to the increasing number of confirmed cases across different regions of the world, the pandemic is taking its toll on almost all country's healthcare systems. Nigeria has had to evoke an emergency operation center that saw the need to upgrade its healthcare facilities and add to NCDC testing centers network across the country to contain COVID-19 spread within her region.

SARS-CoV-2 is a member of the coronaviruses family responsible as well for severe acute respiratory syndrome (SARS-CoV) and Middle East respiratory syndrome (MERSCoV). SARS-CoV-2 spreads rapidly within the community compared to SARS-COV and MERS-CoV which are associated with hospital-acquired infection. ${ }^{60}$ Although COVID-19 fatality rate is lesser compared to SARS and MERS probably due to decline in viral load of COVID-19 patients after the onset of symptoms and as infection progresses into clinical manifestations. ${ }^{61}$ However, COVID-19 is reported to be closely related to SARS and MERS based on demographic features, radiological and laboratory outcomes. ${ }^{62-64}$ In understanding the pathogenicity of COVID-19, genomic analysis revealed that while COVID-19 and SARS share the same human binding receptor - angiotensin-converting enzyme 2 (ACE2), MERS binds to dipeptidyl peptidase 4 (DPP4) to penetrate host cells. ${ }^{65,66}$ Further analysis on binding affinities of coronaviruses showed that COVID-19 binds more efficiently to ACE2 receptor unlike the strains of SARS. ${ }^{65,67,68}$ Could the higher affinity of COVID-19 to ACE2 receptor greatly compromise immune response thus responsible for its faster transmission in the community?

In a study involving young and aged cynomolgus macaques inoculated with clinical isolate of SARS-CoV-2, it was observed that increased age failed to affect disease 
outcome, although there was extended viral shedding in the upper respiratory tract of aged macaques. ${ }^{69}$ After 4 days of viral inoculation, SARS-COV-2 antigen was detected in ciliated epithelial cells of nasal mucosae which was not found in animals infected with SARS-CoV 70 or MERS-COV. ${ }^{69}$ COVID-19 was majorly resident and detected in the respiratory tract airways as well as partly in the stool ${ }^{71}$; however, a recent study reported its presence in the intestine. ${ }^{72}$ Notably, increased viral shedding for SARS-COV-2 in the early days of infection is similar to that of influenza ${ }^{73}$ and could contribute to the challenges in case detection, contact tracing and isolation of COVID-19 patients unlike the rapid success achieved in the control of SARS-COV. ${ }^{74}$

Given the standard of hygiene in Nigeria and its environs that is incomparable to some developed and other developing countries of the world, the Nigerian population might have developed innate and/or adaptive immunity that favors resistance against certain pathogens and infections. Some other factors such as diet, geographical location and genetics might elicit similar outcomes. This may partly explain the low severity of COVID-19 pandemic outbreak being experienced in Nigeria. However, the cases are yet rising with community transmission and the events are becoming unpredictable. Considering this fact and lessons learned from other coronaviruses family, Nigeria should strengthen preventive measures in the healthcare institutions against COVID-19 unending spread.

\section{REFLECTION ON NIGERIA WEATHER AND ITS IMPACT ON COVID-19 TRANSMISSION}

Nigeria, with a population of approximately 200 million, has had cases of emerging and reemerging viral diseases. ${ }^{75}$ This highlights the collective impacts of rapid population growth, social and environmental factors, technological advancement, and other lifestyle changes as contributors to transmission dynamics. Like in many other countries, sporadic outbreaks of viral infections have occurred with time in Nigeria. The NCDC previously reported that the seasonality of Lassa fever virus and influenza outbreaks is debatable as studies have attributed its rapid transmission to both wet and dry seasons. ${ }^{9}$ However, a flu-like respiratory infection has reemerged in the form of COVID-19, and it remains unclear how seasonality modulates its transmission dynamics.

One may argue that seasonal flu and the COVID-19 infection are not the same, but it is also true that both are caused by viruses that show a similar pattern for their survival. Reports showing direct person-to-person or fomites transmission of COVID-19 have been established. ${ }^{76,77}$ Since the rainy season is likely to keep more people indoors with increasing interactions, this raises a concern for what is to be expected by our healthcare system should COVID-19 cases peak in the rainy season. During the rainy season, there is the propensity of overcrowding in various spaces [such as filling stations, bus stations, and other enclosed or partly enclosed public facilities] for shade to avoid getting drenched and protection of valuables. This would be contrary to guidelines on social distancing. However, there is another possibility of the rainy season discouraging free movement as many would prefer to be indoors, which might be a model of lockdown social distancing. The possible scenarios are two-faced and it is important to understand these pointy ends.

If the coronavirus infection surges rapidly, the healthcare system will be overwhelmed and more healthcare workers will likely get infected thereby possibly reduce the number of frontline workers to manage infected people. ${ }^{78}$ This indicates the importance to respond and manage cases within our resources and healthcare system capacity. Our target should be to attain a flattened curve and continue to keep the curve below the healthcare system capacity threshold to ensure a continuous reduced number of cases over time. ${ }^{79}$ These suggest the need to flatten the COVID-19 curve with robust and pragmatic preventive measures by both the policymakers and individuals with changing weather.

\section{CONCLUSIONS}

From our perspectives, we predict an upsurge in COVID-19 transmission, but since the virus has not been around for a complete season, scientists have warned against drawing a too-hasty conclusion, coupled with the fact that seasonality is difficult to predict. Keeping track of COVID-19 cases over time as seasons change could create a more accurate picture in appreciating the transmission dynamics of the virus.

Changes in weather constitute stressors that can modulate the interplay of infectious diseases, geographical distribution and humans. ${ }^{80}$ The seasonal variations may affect the disease vector, pathogen or host [human] susceptibility. ${ }^{81,82}$ Temperatures and rainfall are weather conditions that have strong influence on infectious disease outbreaks. ${ }^{82}$ Although changes in weather conditions have been implicated in the outbreak of several infectious diseases, the case appears to be different for COVID-19. Bukhari and Jameel opined the unlikelihood of a weatheraffected slowdown in COVID-19 spread in the US and Europe as high number of cases have been reported across various weather conditions (temperature and humidity) in these regions. ${ }^{83}$ Partly, these observations hold way in Nigeria as COVID-19 cases have been reported across her two weather seasons. However, its current transmission has a staggered pattern as rate of increase during the wet season tends to be higher in comparison to the dry season. It was initially thought that if temperature and humidity patterns could affect COVID-19 transmission, then mitigation was at hand. ${ }^{84}$ But as there is no particular pattern, we thought the changes in weather conditions might be affecting host susceptibility via immune response rather than the virus itself. COVID-19 geometric infectious spread among various populations with different weather condition suggest its transmission dynamics could be independent of weather.

Nevertheless, changes in weather appear to be a crucial factor in COVID-19 transmission dynamics in Nigeria. The ease of lockdown in the first week of May could have adjusted our outcome slightly, but we strongly believe that compulsory "wear a mask" guideline may have nullified that effect. However, we may not yet know the extent of what we have on our hands until Nigeria gets in the peak of the rainy 
season. Just as the "winter is coming" cliché in a Box Office fictional movie - game of thrones- we would like to adopt the same in expressing our narrative, "Rain is coming and it might be a very long night". Immunity boosters would be of utmost need in the face of COVID-19 pandemic as rainfall becomes intense and steady in Nigeria in the coming weeks.

Availability of data and materials: The sources for all data in this work are cited in the manuscript.

Ethics approval and consent to participate: Not Applicable.

Funding: This work was supported by the National Key R\&D Program of China (2019YFA0906100), Key-Area Research and Development Program of Guangdong Province (2019B020201014), and Nanshan pilot team project (LHTD20160004).

Authorship contributions: Authors OAA, AOA and FOA conceived the idea and wrote the manuscript; LOA contributed substantially to the writing; OAA collected data for this manuscript. GOA and DY reviewed the original draft and gave critical suggestions. XC and SEB supervised and reviewed the writing process. All authors read and accepted the final draft of the manuscript.
Competing interests: The authors completed the Unified Competing Interest form at www.icmje.org/coi disclosure.pdf (available upon request from the corresponding author), and declare potential conflicts of interest as stated below. Professor Xiaochun Wan serves on the advisory board of the company Shenzhen BinDeBioTech Co., Ltd as a consultant. Dr. Ganiyu O. Alli-Balogun declares that work was done out of office hours and outside author's host institution. The remaining authors declare that the research was conducted in the absence of any commercial or financial relationships that could be construed as a potential conflict of interest.

\section{Correspondence to:}

Samuel Essien-Baidoo

Department of Medical Laboratory Science

School of Allied Health Sciences

University of Cape Coast, Ghana.

sessien-baidoo@ucc.edu.gh

Professor Xiaochun Wan (PhD)

Centre for Protein and Cell-based Drugs

Institute of Biomedicine and Biotechnology

Shenzhen Institutes of Advanced Technology

Chinese Academy of Sciences

Shenzhen, 518055, PR China.

xc.wan@siat.ac.cn 


\section{REFERENCES}

1. Wu X, Lu Y, Zhou S, Chen L, Xu B. Impact of climate change on human infectious diseases: Empirical evidence and human adaptation. Environ Int. 2016;86:14-23. doi:10.1016/j.envint.2015.09.007

2. Flahault A, de Castaneda RR, Bolon I. Climate change and infectious diseases. Public Health Rev. 2016;37(1):21. doi:10.1186/s40985-016-0035-2

3. Dalhatu IT, Medina-Marino A, Olsen SI, et al. Influenza viruses in Nigeria, 2009-2010: Results from the first 17 months of a national influenza sentinel surveillance system. J Infect. 2012;206(suppl 1):S121-S128. doi:10.1093/infdis/jis584

4. Heikkinen T, Järvinen A. The common cold. Lancet. 2003;361(9351):51-59. doi:10.1016/s0140-6736(03)12 $\underline{162-9}$

5. Price RHM, Graham C, Ramalingam S. Association between viral seasonality and meteorological factors. Sci Rep. 2019;9(1):1-11. doi:10.1038/s41598-018-374 $\underline{81-\mathrm{y}}$

6. Dowell SF. Seasonal variation in host susceptibility and cycles of certain infectious diseases. Emerg Infect Dis. 2001;7(3):369-374. doi:10.3201/eid0703.017301

7. Morand S, Owers KA, Waret-Szkuta A, McIntyre KM, Baylis M. Climate variability and outbreaks of infectious diseases in Europe. Sci Rep.

2013;3(1):1774. doi:10.1038/srep01774

8. Fuhrmann C. The effects of weather and climate on the seasonality of influenza: What we know and what we need to know. Geography Compass. 2010;4(7):718-730. doi:10.1111/j.1749-8198.2010.003 43.X

9. NCDC. Infectious Diseases in Nigeria. http://www.n cdc.gov.ng/diseases/info/. Published 2020. Accessed May 6, 2020.

10. World Meteorological Organization. World Weather Information Service. https://worldweather.w mo.int. Published 2020.

11. NCDC. COVID-19 Situation Reports. Situation Report 1-77. NCDC; 2020. http://www.covid19.ncdc.g ov.ng.

12. Amaya-Mejía AS, O’Farrill-Romanillos PM, Galindo-Pacheco LV, Ortega GV, Mendoza-Zubieta V, LGD-R H, et al. Vitamin D deficiency in patients with common variable immunodeficiency, with autoimmune diseases and bronchiectasis. Rev Alerg Mex. 2013;60:110-116.
13. Czaja AJ, Montano-Loza AJ. Evolving Role of Vitamin D in Immune-Mediated Disease and Its Implications in Autoimmune Hepatitis. Dig Dis Sci. 2019;64(2):324-344. doi:10.1007/s10620-018-5351-6

14. Pfeffer PE, Hawrylowicz CM. Vitamin D and lung disease. Thorax. 2012;67(11):1018-1020. doi:10.1136/ thoraxjnl-2012-202139

15. Greiller CL, Martineau AR. Modulation of the immune response to respiratory viruses by vitamin $\mathrm{D}$. Nutrients. 2015;7(6):4240-4270. doi:10.3390/nu70642 $\underline{40}$

16. Hoffmann M, Kleine-Weber H, Schroeder S, et al. SARS-CoV-2 cell entry depends on ACE2 and TMPRSS 2 and is blocked by a clinically proven protease inhibitor. Cell. 2020;181(2):271-280.e8. do i:10.1016/i.cell.2020.02.052

17. Hamming I, Timens W, Bulthuis M, Lely A, Navis $\mathrm{G}$, van Goor $\mathrm{H}$. Tissue distribution of ACE2 protein, the functional receptor for SARS coronavirus. A first step in understanding SARS pathogenesis. J Pathol. 2004;203(2):631-637. doi:10.1002/path.1570

18. Bombardini T, Picano E. Angiotensin-Converting Enzyme 2 as the Molecular Bridge Between Epidemiologic and Clinical Features of COVID-19. Can J Cardiol. 2020;36(5):784.e1-784.e2. doi:10.1016/ j.cjca.2020.03.026

19. Nair R, Maseeh A. Vitamin D: The "sunshine" vitamin. Pharmacol Pharmacother. 2012;3:118-126.

20. Holick MF. Vitamin D deficiency. $N$ Engl J Med. 2007;357(3):266-281. doi:10.1056/nejmra070553

21. Gombart AF, Pierre A, Maggini S. A Review of Micronutrients and the Immune System-Working in Harmony to Reduce the Risk of Infection. Nutrients. 2020;12(1):236. doi:10.3390/nu12010236

22. Arshad MS, Khan U, Sadiq A, Khalid W, Hussain $\mathrm{M}$, Yasmeen A, et al. Coronavirus Disease (COVID - 19) and Immunity Booster Green Foods: A Mini Review. Food Sci Nutr. 2020:2449-2450.

23. Glew RH, Crossey MJ, Polanams J, Okolie HI, VanderJagt DJ. Vitamin D Status of Seminomadic Fulani Men and Women. J Natl Med Assoc. 2010;102(6):485-490. doi:10.1016/s0027-9684(15)305 56-3 
24. Owie E, Afolabi BB. Vitamin D deficiency in pregnant women and newborns in Lagos, Nigeria. Journal of Obstetrics and Gynaecology. 2018;38(5):616-621. doi:10.1080/01443615.2017.1396 $\underline{299}$

25. Meehan M, School of Nursing, Loyola University Chicago, IL., USA, Penckofer S. The Role of Vitamin D in the Aging Adult. J Aging Gerontol. 2014;2(2):60-71. doi:10.12974/2309-6128.2014.02.02.1

26. Yancy CW. COVID-19 and African Americans. JAMA. 2020;323(19):1891. doi:10.1001/jama.2020.654 $\underline{8}$

27. Alzaman NS, Dawson-Hughes B, Nelson J, D’Alessio D, Pittas AG. Vitamin D status of black and white Americans and changes in vitamin $\mathrm{D}$ metabolites after varied doses of vitamin $\mathrm{D}$ supplementation. Am J Clin Nutr.

2016;104(1):205-214. doi:10.3945/ajen.115.129478

28. Calder PC, Carr AC, Gombart AF, Eggersdorfer M. Optimal Nutritional Status for a Well-Functioning Immune System Is an Important Factor to Protect against Viral Infections. Nutrients. 2020;12(4):1181. $\underline{\mathrm{d}}$ oi:10.3390/nu12041181

29. Zabetakis I, Lordan R, Norton C, Tsoupras A. COVID-19: The Inflammation Link and the Role of Nutrition in Potential Mitigation. Nutrients. 2020;12(5):1466. doi:10.3390/nu12051466

30. Ali N. Role of vitamin D in preventing of COVID-19 infection, progression and severity. $J$ Infect. June 2020. doi:10.1016/i.jiph.2020.06.021

31. Jayawardena R, Sooriyaarachchi P, Chourdakis M, Jeewandara C, Ranasinghe P. Enhancing immunity in viral infections, with special emphasis on COVID-19: A review. Diabetes Metab Syndr. 2020;14(4):367-382. doi:10.1016/i.dsx.2020.04.015

32. Arboleda Alzate JF, Rodenhuis-Zybert IA Hernández JC, Smit JM, Urcuqui-Inchima S. Human macrophages differentiated in the presence of vitamin D3 restrict dengue virus infection and innate responses by downregulating mannose receptor expression. de Silva AM, ed. PLoS Negl Trop Dis. 2017;11(10):e0005904-e. doi:10.1371/journal.pntd.00 $\underline{05904}$

33. Arboleda JF, Urcuqui-Inchima S. Vitamin D Supplementation: A Potential Approach for Coronavirus/COVID-19 Therapeutics? Front Immunol. 2020;11:1523. doi:10.3389/fimmu.2020.015 $\underline{23}$
34. Daneshkhah A, Agrawal V, Eshein A, Subramanian $\mathrm{H}$, Roy HK, Backman V. The Possible Role of Vitamin D in Suppressing Cytokine Storm and Associated Mortality in COVID-19 Patients. medRxiv. April 2020. doi:10.1101/2020.04.08.20058578

35. Ebadi M, Montano-Loza AJ. Perspective: Improving vitamin D status in the management of COVID-19. Eur J Clin Nutr. 2020;74(6):1-4. doi:10.103 8/s41430-020-0661-0

36. Mitchell F. Vitamin-D and COVID-19: Do deficient risk a poorer outcome? Lancet Diabetes Endocrinol. 2020;8(7):570. doi:10.1016/s2213-8587(2 0)30183-2

37. Pauling L. Vitamin C and common cold. JAMA. 1971;216(2):332. doi:10.1001/jama.1971.03180280086 $\underline{025}$

38. Hernández A, Papadakos PJ, Torres A, González DA, Vives M, Ferrando C, et al. Two known therapies could be useful as adjuvant therapy in critical patients infected by COVID-19. Rev Esp Anestesiol Reanim. 2020;67:245-252.

39. Carr AC, Maggini S. Vitamin C and Immune Function. Nutrients. 2017;9(11):1211. doi:10.3390/nu $\underline{9111211}$

40. van Gorkom GNY, Klein Wolterink RGJ, Van Elssen C, Wieten L, Germeraad WTV, Bos GMJ. Influence of Vitamin C on Lymphocytes: An Overview. Antioxidants. 2018;7(3):41. doi:10.3390/antiox70300 $\underline{41}$

41. Carr AC, Rosengrave PC, Bayer S, Chambers S, Mehrtens J, Shaw GM. Hypovitaminosis $C$ and vitamin $\mathrm{C}$ deficiency in critically ill patients despite recommended enteral and parenteral intakes. Crit Care. 2017;21(1):300. doi:10.1186/s13054-017-1891-y

42. Carr AC. A new clinical trial to test high-dose vitamin C in patients with COVID-19. Crit Care. 2020;24(1):133. doi:10.1186/s13054-020-02851-4

43. Chen L, Liu HG, Liu W, Liu J, Liu K, Shang J, et al. Analysis of clinical features of 29 patients with 2019 novel coronavirus pneumonia. Zhonghua Jie He He Hu Xi Za Zhi. 2020;43:203-208.

44. Shanghai Expert Panel. http://mp.weixin.qq.com/ s? biz=MzA3Nzk5Mzc5MQ==\&mid=2653620168\&id $\mathrm{x}=1 \& \mathrm{sn}=2352823 \mathrm{~b} 79 \mathrm{a} 3 \mathrm{cc} 42 \mathrm{e} 48229 \mathrm{a} 0 \mathrm{c} 38 \mathrm{f} 65 \mathrm{e} 0$ \&chks $\underline{m=84962598 b 3 e 1 a c 8 e f f b 763 e 3 d d b 4858435 d c 7 a a 947 a}$ 8f41790e8df2bca34c20e6ffea64cd191\#rd; Published 2020.

45. 45 High-Dose Vitamin C $\left(P D Q{ }^{\circledR}\right)$-Health

Professional Version. National Cancer Institute; 2020. 
46. Nilashi M, Samad S, Shahmoadi L, Ahmadi H, Akbari E, Rashid TA. The COVID-19 infection and the immune system: The role of complementary and alternative medicines. Biomed Res (Aligarh). 2020;31.

47. Chowdhury FR, Ibrahim QSU, Bari MS, et al. The association between temperature, rainfall and humidity with common climate-sensitive infectious diseases in Bangladesh. Khan HTA, ed. PLoS ONE. 2018;13(6):e0199579. doi:10.1371/journal.pone.0199 $\underline{579}$

48. Fisman D. Seasonality of viral infections: Mechanisms and unknowns. Clin Microbiol Infect. 2012;18(10):946-954. doi:10.1111/j.1469-0691.2012.0 3968.x

49. Foxman EF, Storer JA, Vanaja K, Levchenko A, Iwasaki A. Two interferon-independent doublestranded RNA-induced host defense strategies suppress the common cold virus at warm temperature. Proc Natl Acad Sci USA. 2016;113(30):8496-8501. doi:10.1073/pnas.16019421 $\underline{13}$

50. Xu D-L, Hu X-K, Tian Y-F. Effect of temperature and food restriction on immune function in striped hamsters (Cricetulus barabensis). J Exp Biol. 2017;220(12):2187-2195. doi:10.1242/jeb.153601

51. Chen Y, Hamati E, Lee P-K, et al. Rhinovirus induces airway epithelial gene expression through double-stranded RNA and IFN-dependent pathways. Am J Respir Cell Mol Biol. 2006;34(2):192-203. doi:1 0.1165/rcmb.2004-0417oc

52. Foxman EF, Storer JA, Fitzgerald ME, et al. Temperature-dependent innate defense against the common cold virus limits viral replication at warm temperature in mouse airway cells. Proc Natl Acad Sci USA. 2015;112(3):827-832. doi:10.1073/pnas.1411030 $\underline{112}$

53. LaVoy ECP, McFarlin BK, Simpson RJ. Immune responses to exercising in a cold environment. Wild Environ Med. 2011;22(4):343-351. doi:10.1016/i.we $\underline{\text { m.2011.08.005 }}$

54. Zheng M, Gao Y, Wang G, et al. Functional exhaustion of antiviral lymphocytes in COVID-19 patients. Cell Mol Immunol. 2020;17(5):533-535. do $\mathrm{i}: 10.1038 / \mathrm{s} 41423-020-0402-2$

55. Qin C, Zhou L, Hu Z, et al. Dysregulation of Immune Response in Patients With Coronavirus 2019 (COVID-19) in Wuhan, China. Clin Infect Dis. 2020;71(15):762-768. doi:10.1093/cid/ciaa248
56. Antonioli L, Fornai M, Pellegrini C, Blandizzi C. NKG2A and COVID-19: Another brick in the wall. Cell Mol Immunol. 2020;17(6):1-3. doi:10.1038/s41423-02 0-0450-7

57. Xie J, Zhu Y. Association between ambient temperature and COVID-19 infection in 122 cities from China. Sci Total Environ. 2020;724:138201. do i:10.1016/i.scitotenv.2020.138201

58. Pastorino B, Touret F, Gilles M, de Lamballerie X, Charrel RN. Evaluation of heating and chemical protocols for inactivating SARS-CoV-2. bioRxiv. April 2020. doi:10.1101/2020.04.11.036855

59. NCDC. First case of coronavirus disease confirmed in Nigeria. 2020.

60. Munster VJ, Koopmans M, van Doremalen N, van Riel D, de Wit E. A Novel Coronavirus Emerging in China - Key Questions for Impact Assessment. N Engl J Med. 2020;382(8):692-694. doi:10.1056/nejmp20009 $\underline{29}$

61. Petrosillo N, Viceconte G, Ergonul O, Ippolito G, Petersen E. COVID-19, SARS and MERS: Are they closely related? Clinical Microbiology and Infection. 2020;26(6):729-734. doi:10.1016/j.cmi.2020.03.026

62. Chen N, Zhou M, Dong X, et al. Epidemiological and clinical characteristics of 99 cases of 2019 novel coronavirus pneumonia in Wuhan, China: A descriptive study. Lancet. 2020;395(10223):507-513. 때 oi:10.1016/s0140-6736(20)30211-7

63. Chung M, Bernheim A, Mei X, et al. CT Imaging Features of 2019 Novel Coronavirus (2019-nCoV). Radiology. 2020;295(1):202-207. doi:10.1148/radiol.2 $\underline{020200230}$

64. Xie X, Zhong Z, Zhao W, Zheng C, Wang F, Liu J. Chest CT for Typical 2019-nCoV Pneumonia: Relationship to Negative RT-PCR Testing. Radiology. 2020:200343.

65. Wan Y, Shang J, Graham R, Baric RS, Li F. Receptor Recognition by the Novel Coronavirus from Wuhan: An Analysis Based on Decade-Long Structural Studies of SARS Coronavirus. Gallagher T, ed. J Virol. 2020;94(7). doi:10.1128/jvi.00127-20

66. Walls AC, Park Y-J, Tortorici MA, Wall A, McGuire AT, Veesler D. Structure, Function, and Antigenicity of the SARS-CoV-2 Spike Glycoprotein. Cell. 2020;181(2):281-292.e6. doi:10.1016/i.cell.2020.02.05 $\underline{8}$ 
67. Tai W, He L, Zhang X, et al. Characterization of the receptor-binding domain (RBD) of 2019 novel coronavirus: Implication for development of RBD protein as a viral attachment inhibitor and vaccine. Cell Mol Immunol. 2020;17(6):1-8. doi:10.1038/s4142 3-020-0400-4

68. Shang J, Ye G, Shi K, et al. Structural basis of receptor recognition by SARS-CoV-2. Nature. 2020;581(7807):221-224. doi:10.1038/s41586-020-21 $\underline{79-\mathrm{y}}$

69. Rockx B, Kuiken T, Herfst S, et al. Comparative pathogenesis of COVID-19, MERS, and SARS in a nonhuman primate model. Science.

2020;368(6494):1012-1015. doi:10.1126/science.abb7 $\underline{314}$

70. Kuiken T, Fouchier RA, Schutten M, et al. Newly discovered coronavirus as the primary cause of severe acute respiratory syndrome. Lancet.

2003;362(9380):263-270. doi:10.1016/s0140-6736(0 3) $13967-0$

71. Holshue ML, DeBolt C, Lindquist S, et al. First Case of 2019 Novel Coronavirus in the United States. N Engl J Med. 2020;382(10):929-936. doi:10.1056/nej moa2001191

72. Xiao F, Tang M, Zheng X, Liu Y, Li X, Shan H. Evidence for gastrointestinal infection of SARSCoV-2. Gastroenterology. 2020;158(6):1831-1833.e3. doi:10.1053/i.gastro.2020.02.055

73. Li C-C, Wang L, Eng H-L, et al. Correlation of pandemic (H1N1) 2009 viral load with disease severity and prolonged viral shedding in children. Emerg Infect Dis. 2010;16(8):1265-1272. doi:10.3201/eid160 8.091918

74. Pang X, Zhu Z, Xu F, Guo J, Gong X, Liu D, et al. Evaluation of control measures implemented in the severe acute respiratory syndrome outbreak in Beijing, 2003. JAMA. 2003;290(24):3215-3221. doi:1 $\underline{0.1001 / \text { jama.290.24.3215 }}$

75. Fagbami AH, Onoja AB. Dengue haemorrhagic fever: An emerging disease in Nigeria, West Africa. $J$ Infect. 2018;11(6):757-762. doi:10.1016/j.jiph.2018.0 $\underline{4.014}$
76. Chan JF-W, Yuan S, Kok K-H, et al. A familial cluster of pneumonia associated with the 2019 novel coronavirus indicating person-to-person transmission: A study of a family cluster. Lancet. 2020;395(10223):514-523. doi:10.1016/s0140-6736(2 0)30154-9

77. Li Q, Guan X, Wu P, Wang X, Zhou L, Tong Y, et al. Early transmission dynamics in Wuhan, China, of novel coronavirus-infected pneumonia. $N$ Engl J Med. 2020 .

78. Anderson RM, Heesterbeek H, Klinkenberg D, Hollingsworth TD. How will country-based mitigation measures influence the course of the COVID-19 epidemic? Lancet. 2020;395(10228):931-934. doi:10.1 016/s0140-6736(20)30567-5

79. Matrajt L, Leung T. Evaluating the Effectiveness of Social Distancing Interventions to Delay or Flatten the Epidemic Curve of Coronavirus Disease. Emerg Infect Dis. 2020;26(8):1740-1748. doi:10.3201/eid260 $\underline{8.201093}$

80. Morand S, Owers KA, Waret-Szkuta A, McIntyre $\mathrm{KM}$, Baylis M. Climate variability and outbreaks of infectious diseases in Europe. Sci Rep. 2013;3(1):1774. doi:10.1038/srep01774

81. Metcalf CJE, Walter KS, Wesolowski A, et al. Identifying climate drivers of infectious disease dynamics: Recent advances and challenges ahead. Proc R Soc B. 2017;284(1860):20170901. doi:10.1098/r spb.2017.0901

82. Fouque F, Reeder JC. Impact of past and on-going changes on climate and weather on vector-borne diseases transmission: A look at the evidence. Infect Dis Poverty. 2019;8(1):51. doi:10.1186/s40249-019-05 65-1

83. Bukhari Q, Jameel Y. Will Coronavirus Pandemic Diminish by Summer? SSRN Journal. 2020. doi:10.213 9/ssrn.3556998

84. Sajadi MM, Habibzadeh P, Vintzileos A, Shokouhi S, Miralles-Wilhelm F, Amoroso A. Temperature and latitude analysis to predict potential spread and seasonality for COVID-19. SSRN Journal. 2020. doi:1 $0.2139 /$ ssrn. 3550308 